\title{
The Synthesis of a Pyrazol Analogon of Porphobilinogen with the Help of the Mukaiyama Aldol Reaction
}

\author{
André Chaperon, Hugo Bertschy, Anne-Laurence Franz-Schrumpf, Bertrand Hugelet, Antonia \\ Neels, Helen Stoeckli-Evans, and Reinhard Neier*
}

\begin{abstract}
The synthesis of a pyrazol analogon of porphobilinogen is described. The Mukaiyama crossed aldol reaction is the key step of our approach. The retrosynthetic analysis follows the mechanism for the biosynthesis of porphobilinogen initially proposed by Shemin.
\end{abstract}

Keywords: Biomimetic synthesis · Mukaiyama aldol reaction $\cdot$ Porphobilinogen $\cdot$ Silyl enol ether

The tetrapyrrolic pigments assume important roles in many vital processes of life [1]. Therefore the tetrapyrroles have been called the 'pigments of life' [2]. In the fifties the structures of the biosynthetic intermediates leading to the first tetrapyrrole, uroporphyrinogen III, was determined (Scheme 1) [3][4]. Once the biosynthetic formation of the tetrapyrrole skeleton was known, the interest focused on the steps from this common intermediate to the individual representatives of the 'pigments of life' especially heme and the chlorophylls [5]. In the early seventies it was shown that the first steps of the biosynthesis of vitamin $\mathrm{B}_{12}$ follow the same pathway as the other 'pigments of life' [6-9]. For the following two decades intensive efforts were dedicated to the elucidation of the final steps in the biosynthesis of vitamin $\mathrm{B}_{12}$ using classical methods [3][4][10]. Intensive efforts were dedicated to this problem during this period, but the progress was rather slow. Only three out of nine intermediates could be isolated and characterized.

\footnotetext{
${ }^{*}$ Correspondence: Prof. Dr. R. Neier Institut de Chimie

Université de Neuchâtel

Case postale 2

CH-2007 Neuchâtel

Tel.: +4132 7182428

Fax: +41327182511

E-Mail: reinhard.neier@unine.ch

www.unine.ch/chim/neier/welcome.htm
}

The elucidation of the biosynthesis of vitamin $B_{12}$ was finally achieved in the early nineties using the power of molecular biology [11][12]. Once the genes of the biosynthetic pathway to vitamin $B_{12}$ had been identified and cloned, the elusive intermediates between uroporphyrinogen III and the corrin chromophore could be isolated. As sufficient quantities of these intermediates became available their structures could be determined in a relatively short time using the methods of modern NMRspectroscopy.

The start of the tetrapyrrol biosynthesis synthesizing uroporphyrinogen III from eight molecules of $\delta$-aminolevulinate in three efficient steps still attracted the attention of many scientists (Scheme 1). The biosynthesis of uroporphyrinogen III is highly convergent. None of the published chemical syntheses can be compared with the biosynthesis as far as efficiency and convergency is concerned (Scheme 2) [13] [14]. The second and third enzymatic step leading from porphobilinogen (PBG) to uroporphyrinogen III could be imitated in the test tube just three years after the structure determination of porphobilinogen [15][16].

Therefore the question was asked if also step one, the biosynthesis of porphobilinogen, might be reproduced in the absence of an enzyme. So far no simple solution for this problem has been found despite considerable efforts [17]. This is all the more amazing as the biosynthesis of porphobilinogen corresponds to a simple Knorr synthesis, whereas the biosynthesis of uroporphyrinogen III represents a more complex reaction sequence [18]. Arguments based on biological observations and chemical experiments conveyed the idea that vitamin $\mathrm{B}_{12}$ or at least a molecule containing the chromophore of vitamin $B_{12}$ had been present in the prebiotic phase. Based on this hypothesis a systematic search for potentially prebiotic syntheses was undertaken [19]. In a series of impressive and very elegant experiments a synthesis of des(amino methyl)porphobilinogen dinitrile using glutamine nitrile as starting material was developed (Scheme 3) [20]. The postulated prebiotic reaction differs considerably from the mechanism of today's biosynthesis. In this context our group studies transformations imitating the mechanism for the biosynthesis of PBG, suggested by Shemin [21]. It is the goal of our studies to develop a high-yielding synthesis of analogues to porphobilinogen and if possible of porphobilinogen itself, imitating nature's retrosynthetic approach [22-24].

In an earlier short communication we presented the successful application of our approach to obtain a protected form of porphobilinogen [23]. We report here on our attempts to form regioselectively the silyl enol ether of protected derivatives of 5 -aminolaevulinate and on its use in the Mukaiyama aldol reaction [25] for the synthesis of a pyrazol analogon of porphobilinogen. Pyrazols are structurally similar to pyrroles. Based on sterics only, a pyrazol 


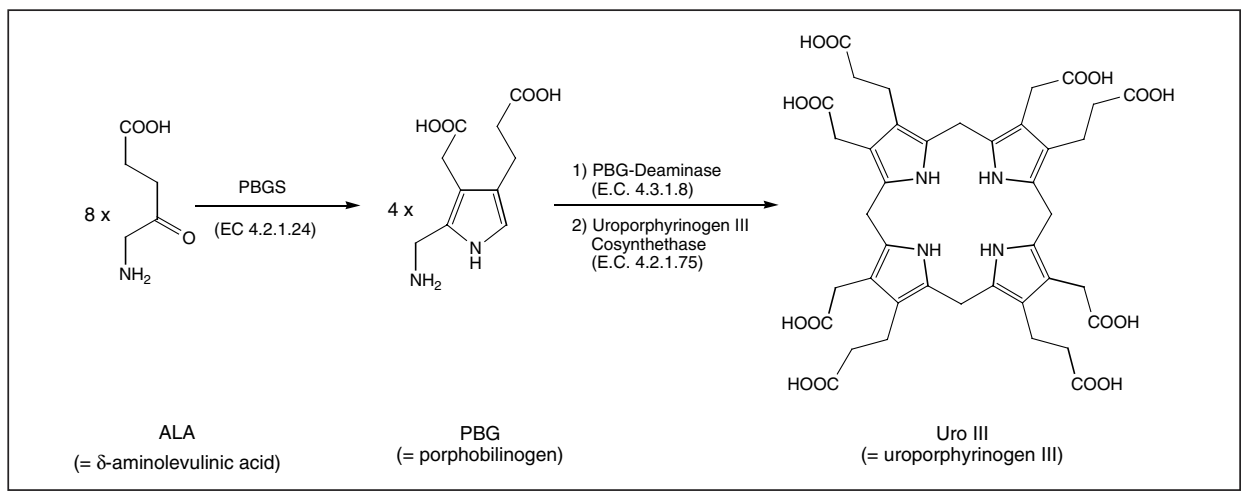

Scheme 1.

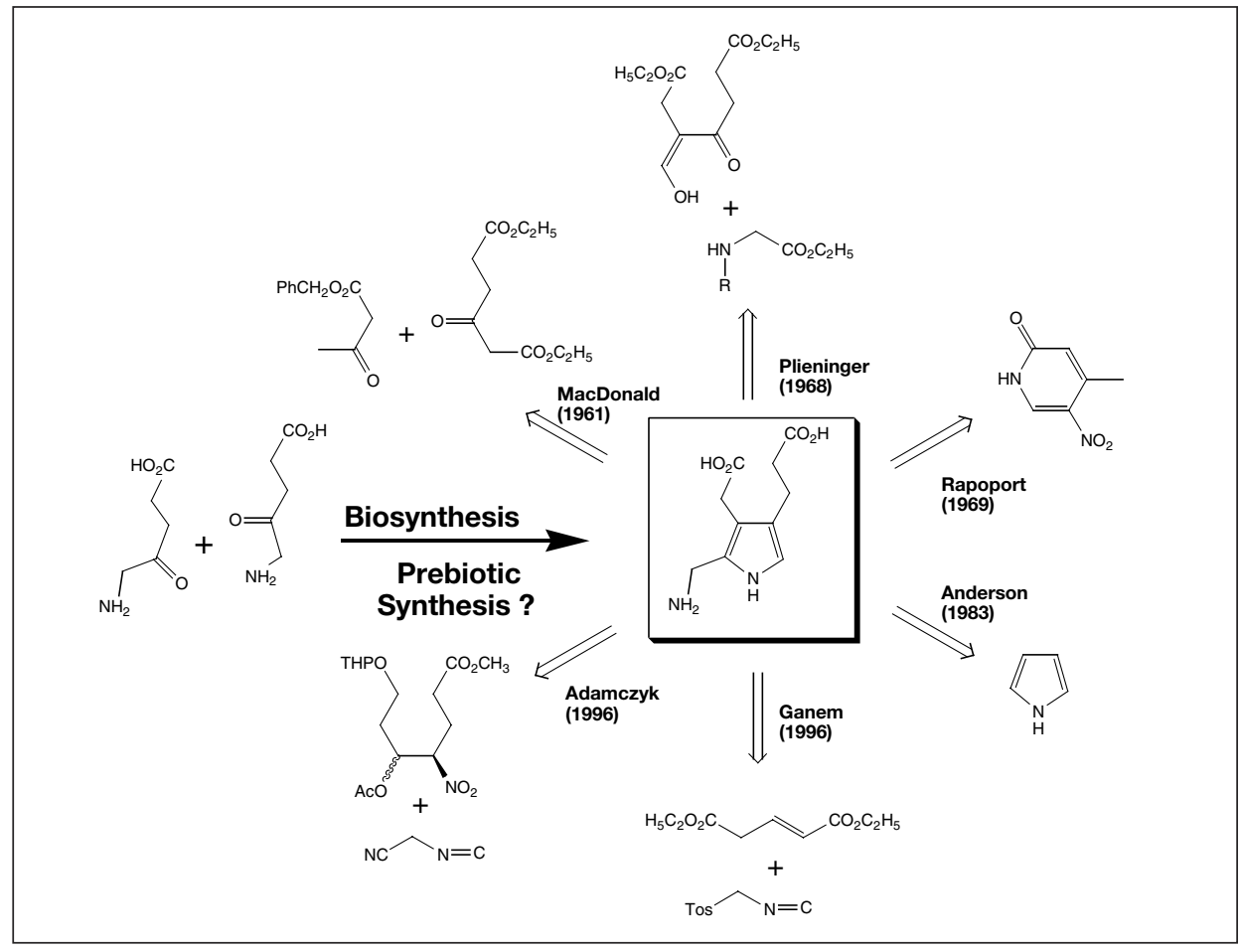

Scheme 2.

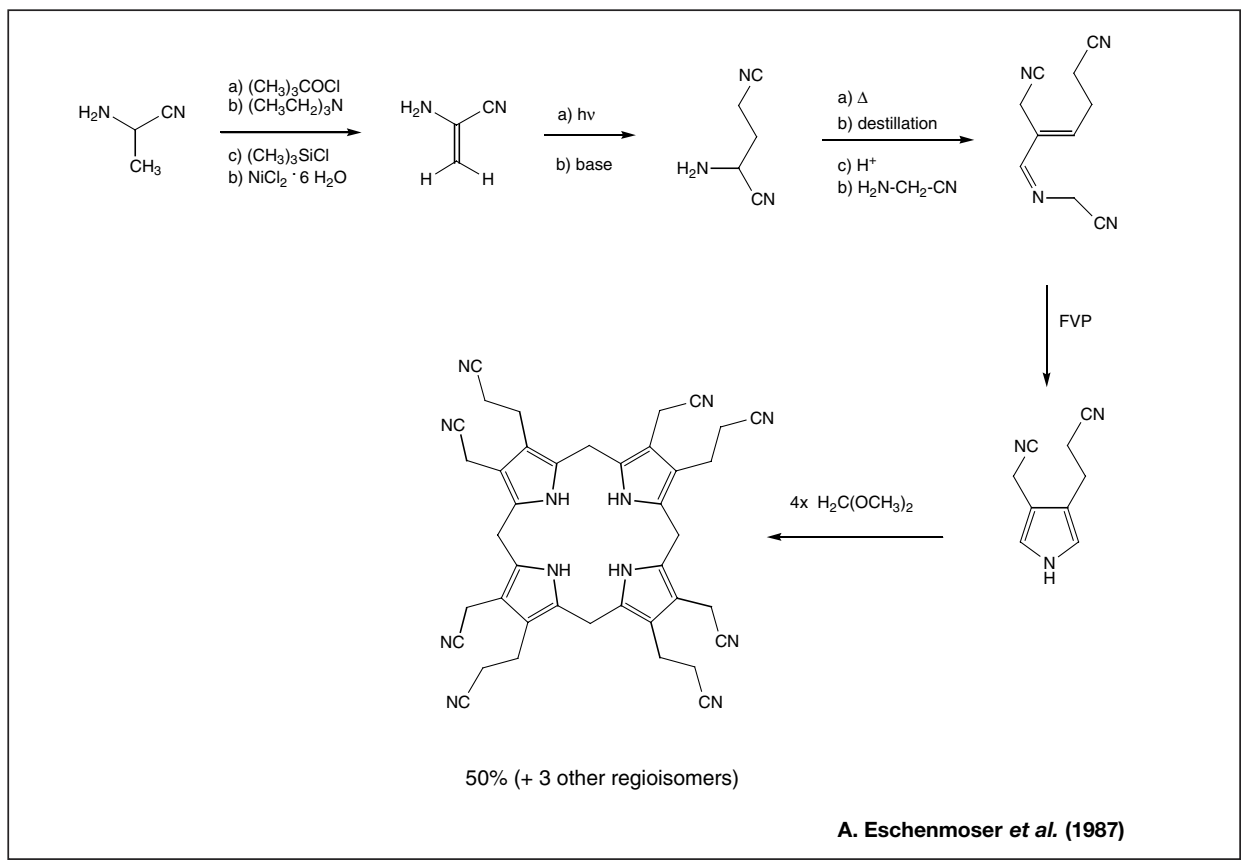

Scheme 3. analogue of PBG should be easily recognized by the enzymes of the tetrapyrrol biosynthetic pathway. The second pyridinelike nitrogen in the pyrazole reduces the reactivity of this heterocycle towards electrophiles substantially, leading to higher stability [26]. Adequately substituted pyrazols represent interesting product analogues for the enzyme porphobilinogen synthase (PBGS or $\delta$-aminolaevulinic acid dehydratase or EC 4.2.1.24) and they should be substrate analogues for the hydroxymethylbilane synthase (HMBS or porphobilinogen deaminase, EC 4.3.1.8), the enzyme catalyzing the next step in the biosynthesis of tetrapyrroles.

We intended to apply our two-step synthesis of alkyl-substituted pyrroles to obtain structural analogues to PBG. The sequence consists of a Mukaiyama aldol reaction followed by the reduction of the azido function, leading directly to the appropriate pyrrole (Scheme 4) [22-24]. To apply our strategy, a protected derivative of the 5-aminolevulinate has to be transformed regioselectively into the appropriate silyl enol ether. Applying the Miller conditions [27] to convert 1a or the ethyl 5-tert.butyldimethylsilyloxy-levulinate $\mathbf{1 b}$ into the corresponding silyl enol ether $\mathbf{2 a}$ and $\mathbf{2} \mathbf{b}$ (Table) lead primarily or exclusively to the unwanted regioisomers. Silyation of methyl 5-chlorolevulinate 1c preceded with an improved but still unsatisfactory regioselectivity (2c/3c 59:41). Methyl 5-bromlevulinate 1d was not stable under the Miller conditions. Also under house conditions [28] no silyl enol ether could be isolated. Replacing DMF as a solvent by $\mathrm{CH}_{2} \mathrm{Cl}_{2}$ and adding DMAP, the silyl enol ether could be isolated in $60 \%$ total yield from 1d. Under these modified house conditions $40 \%$ of the elimination product and only $20 \%$ of the undesired regioisomer $\mathbf{3 d}$ were isolated. Applying TMS-triflate in slight excess in presence of TEA a product mixture containing the regioisomeric silyl enol ether $\mathbf{2 d}$ and 3d was obtained. If a $20 \mathrm{~mol} \%$ surplus of TMS-triflat was added after a short reaction time, equilibration of the mixture could be achieved over a period of $15 \mathrm{~d}$. Under these conditions $73 \%$ yield of a mixture could be isolated, containing the two diastereoisomers of the silyl enol ether $\mathbf{3 d}$ the silyl enol ether $\mathbf{2 d}$ and the starting material 1d (37\%:13\%:23\%).

A solution to the synthetic problem could be finally found. Treating methyl 5-phthalimidolevulinate 1e with TMSI and HMDS in chloroform, in analogy to Miller's conditions, the silyl enol ether could be obtained (Scheme 5). Addition of dry hexane led to the precipitation of the salt formed as side product. The desired regioi- 


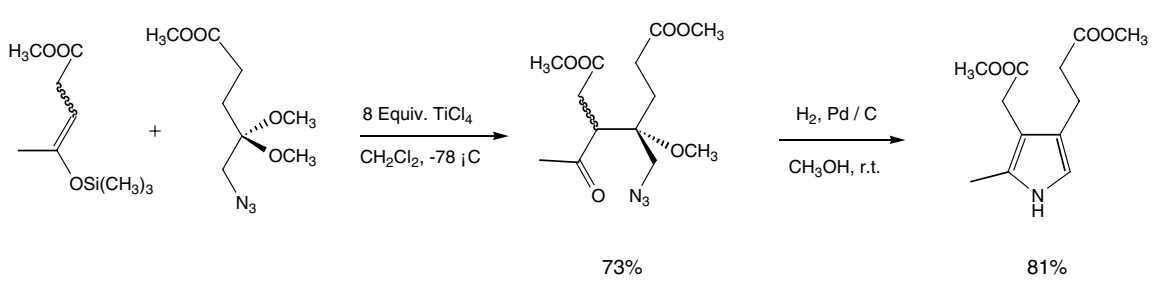

Bertschy et al. (1990)

Scheme 4.

Table. Synthesis of the silyl enol ethers 2 und $\mathbf{3}$.

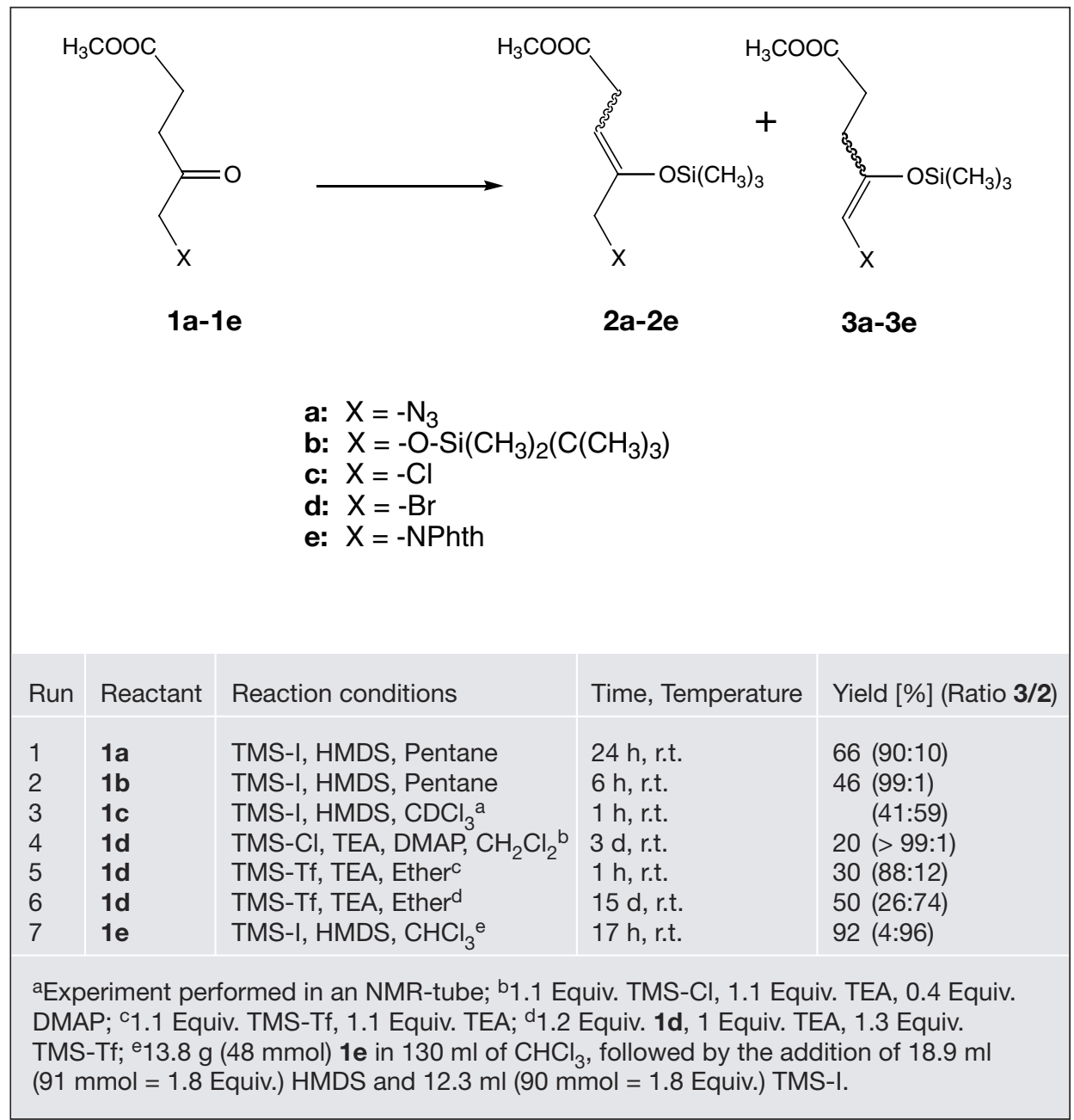

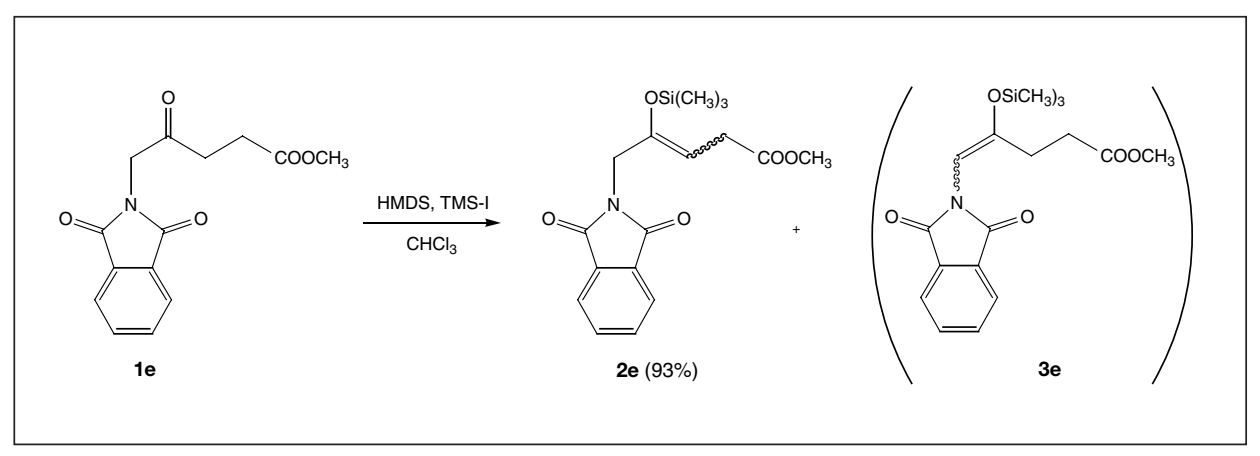

Scheme 5. somer of the silyl enol ether $\mathbf{3 e}$ could be isolated in $93 \%$ yield as 1:1 mixture of the two diastereoisomers contaminated with $4 \%$ of the unwanted regioisomer $\mathbf{2 e}$. The silyl enol ether $\mathbf{3 e}$ could be stored in the freezer at $-20{ }^{\circ} \mathrm{C}$ over months. The regioselectivity of this reaction is surprising, since the protons in the $\alpha$-position of the phthalimido group should be more acidic than the protons at C3. The preferred formation of the regioisomer 3e may be attributed to steric hindrance present in both diastereoisomers of the silyl enol ethers 2e. The X-ray crystal structure of the starting material 1e gives hints favoring this argument (Fig. 1). The phthalimido group is arranged in a plane which is perpendicular to the keto group. Thus the two oxygen atoms of the phthalimido group avoid the unfavorable steric and electronic contacts with the carbonyl oxygen atom. Arranging the phthalimido group in such a way allows a favorable intramolecular $\pi$ - $\pi$-stacking as well. It is therefore difficult to judge the importance of the $\pi$-stacking and/or the lone pair repulsion for the presence of the observed conformer in the crystal structure.

The first attempt to react the silyl enol ether $3 \mathbf{e}$ with the acetal of the methyl 5-azidolevulinate under standard conditions failed [22][23]. Varying the reaction conditions in order to obtain the crucial $\mathrm{C}-\mathrm{C}$ bond did not lead to success. In order to examine the reactivity of $\alpha$-phthalimido silyl enol ethers we synthesized and studied simple model compounds. Reacting phthalimidoacetone (4) with 2 equiv. of TMSI and HMDS in $\mathrm{CHCl}_{3}$ during $3 \mathrm{~h}$ leads to a mixture which contained $90 \%$ of the desired silyl enol ether 5 contaminated with $7 \%$ of the regioisomeric silyl enol ether and 3\% starting material (Scheme 6). Work-up in the absence of water allows the product to be obtained in almost quantitative yield and in good purity. The silyl enol ether 5 was stable in the freezer.

Already the first trial of the Mukaiyama aldol coupling led to positive results. The reaction using dimethyl acetal of methyl levulinate (6) as nucleophile under standard conditions led in $31 \%$ to the aldol product 7. Reacting the acetals of azido acetone (8a) and the methyl 5-azidolevulinate (8b) yielded aldol products in $53 \%$ and $68 \%$ yield, respectively. These two aldol products $9 \mathbf{a}$ and $9 \mathbf{b}$ could be reduced in $46 \%$ and $41 \%$ yield, respectively, to the corresponding pyrroles 10a and 10b (Scheme 6). As catalyst, $\mathrm{Pd}$ on charcoal was used in methanol as a solvent. The ${ }^{1} \mathrm{H}$ - and ${ }^{13} \mathrm{C}$ NMR of samples taken after a short time (less than $3 \mathrm{~h}$ ) indicated the presence of an intermediate, whose spectral data agree well with the $\Delta 1$-pyrrolenine structure 


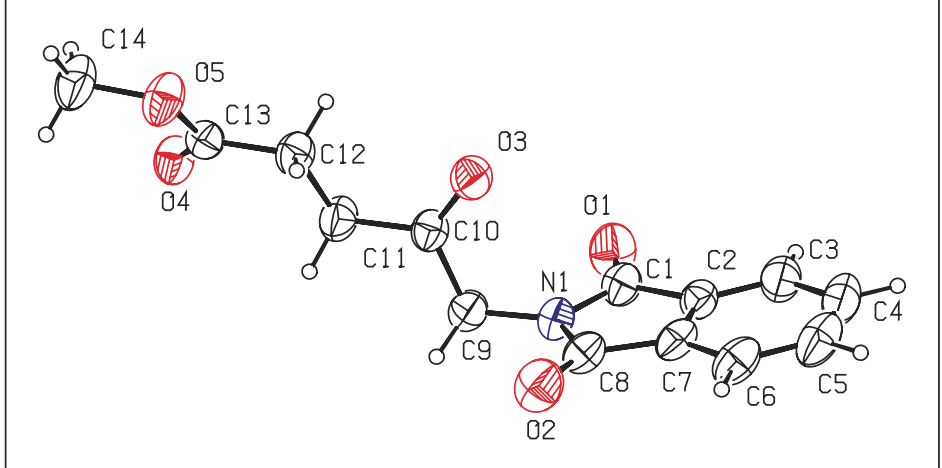

Fig. 1. Perspective view of 1e showing the crystallographic numbering scheme. The thermal ellipsoids are drawn at the $30 \%$ probability level.

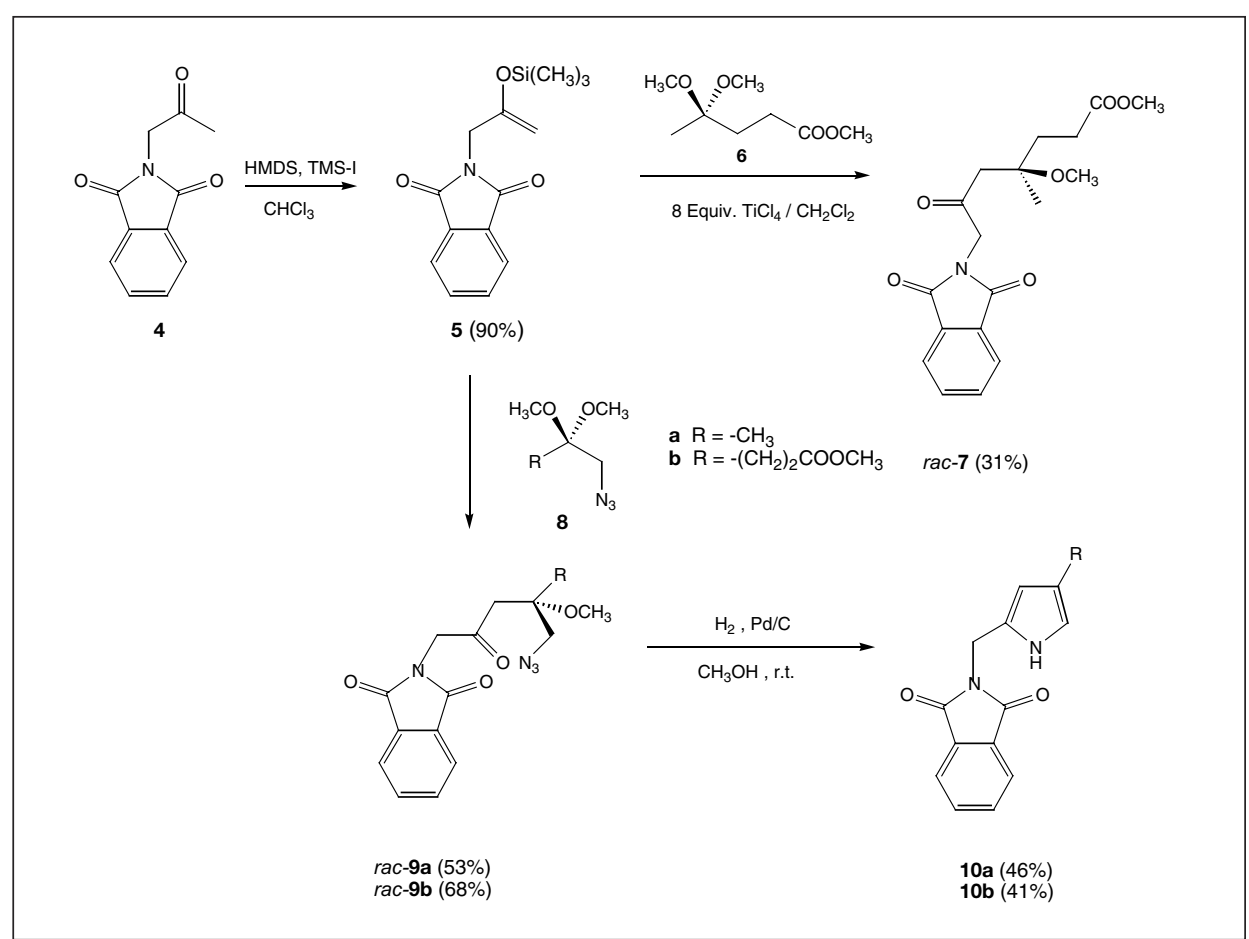

Scheme 6.

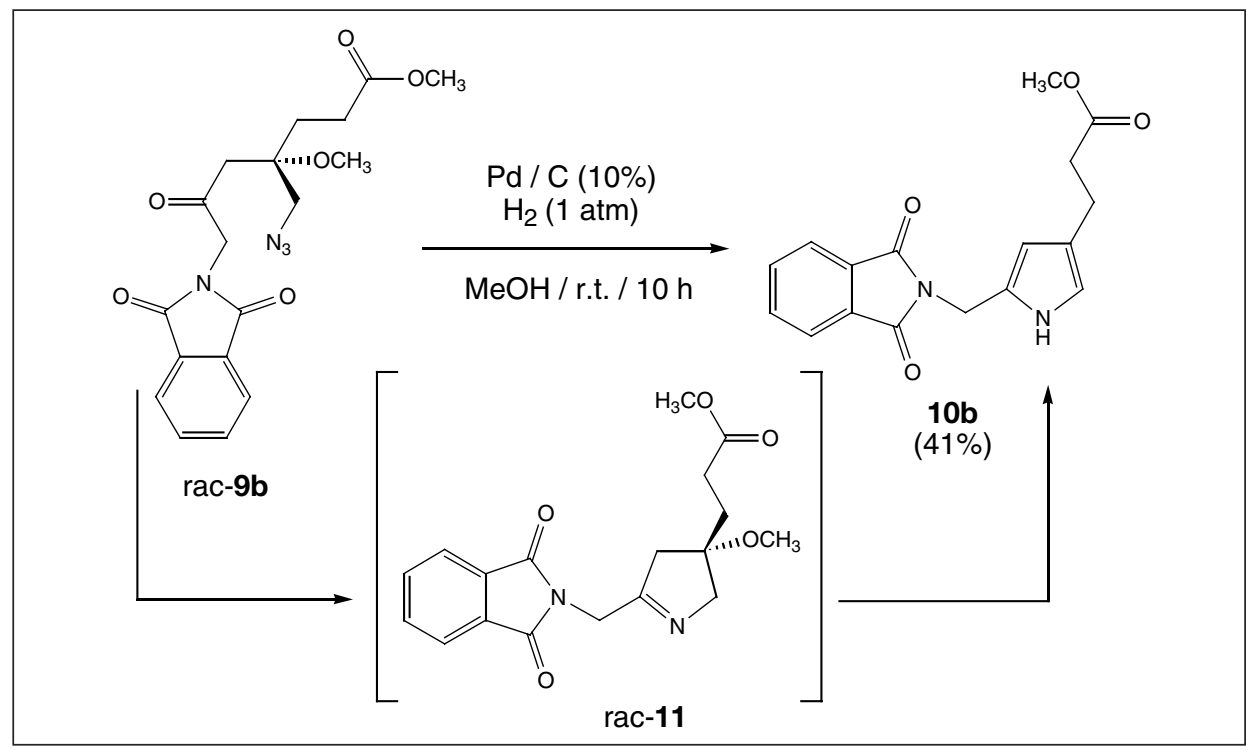

Scheme 7.
(Scheme 7). The pyrrol $\mathbf{1 0 b}$ could be crystallized and its X-ray structure could be determined (Fig. 2). In the crystal the propionic acid side chain is lying in the plane of the pyrrol ring, while the phthalimido group is arranged at an angle to the pyrrol ring. In this arrangement the phthalimido group avoids the allylic $\mathrm{A}^{1,3}$ strain with the pyrrole.

After these successful model studies, we tried to react the silyl enol ether $2 \mathbf{e}$ under our optimized conditions. In order to test the reactivity of the silyl enol ether we tried the crossed aldol coupling using benzaldehyde dimethyl acetal (12) first (Scheme 8). After $3.25 \mathrm{~h}$ reaction time using 1.1 equiv. of $\mathrm{TiCl}_{4}$ as catalyst, the product $\mathbf{1 3}$ could be isolated as crystals in $63 \%$ yield as a 7:3 mixture of the two diastereoisomers. Careful recrystallisation allowed the main diastereoisomer to be obtained in a suitable form to be analyzed by X-ray (Fig. 3). The relative configuration of the main diastereoisomer is unlike. Despite intensive attempts to achieve the Mukaiyama aldol coupling also with derivatives of the protected 5-aminolevulinate we were unable to observe product formation under our conditions. $\mathrm{TiCl}_{4}$ as a catalyst did not induce the aldol reaction using the silyl enol ether $2 \mathbf{e}$ at temperatures below $-40{ }^{\circ} \mathrm{C}$. As soon as the temperature was increased, decomposition occurred. Changing the catalyst using either TMSOTf [29][30] or the 'super Lewis acid' B(OTf)4TMS according to Davis [31] the aldol reaction with the dimethyl acetal of methyl levulinate $(\mathbf{6})$ could be induced. Under Noyori conditions [29] using 0.11 equiv. of TMSOTf as catalyst, $30 \%$ of the pure diastereoisomers $\mathbf{1 4}$ could be isolated. Even using this Lewis acid we could not achieve the crucial $\mathrm{C}-\mathrm{C}$ bond formation with protected precursors of the 5-aminolevulinate. Applying the more reactive and also more aggressive catalyst TMSI [32] led at $-80{ }^{\circ} \mathrm{C}$ to decomposition of the silyl enol ether $\mathbf{2} \mathbf{e}$ as well as the acetals.

Increasing the electrophilicity of the carbonyl component seemed to be the most promising way to achieve the aldol reaction anyway. Therefore we reacted the silyl enol ether $2 \mathbf{e}$ with the succinic acid monochloride and obtained in 35\% yield the desired $\beta$-diketone 15 (Scheme 9). Reacting this diketone with hydrazine hydrate during $1 \mathrm{~h}$ in methanol led in $83 \%$ yield to the pyrazol 16. The protecting groups could be removed by refluxing 16 in $1 \mathrm{~N} \mathrm{HCl}$ during $24 \mathrm{~h}$. Separation of the pyrazole analogon 17 of PBG from phthalic acid could be achieved filtering the raw material over an Amberlite XAD-2 ion exchange column. An $87 \%$ yield of $\mathbf{1 7}$ could be isolated. The 


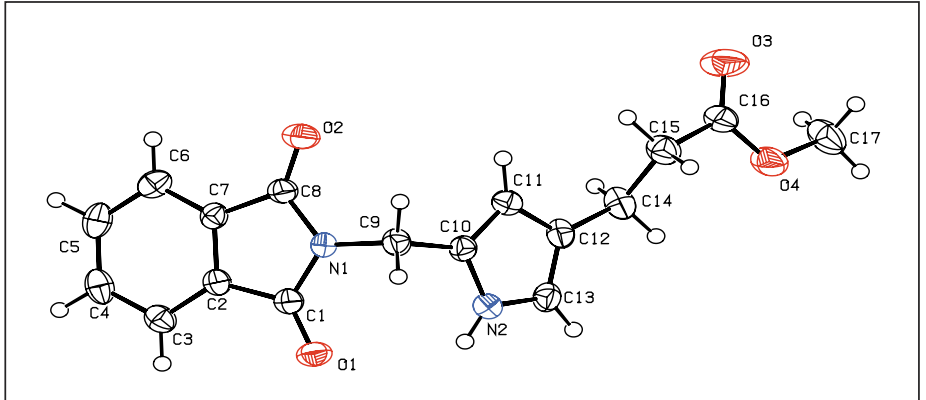

Fig. 2. Perspective view of $\mathbf{1 0 b}$ showing the crystallographic numbering scheme. The thermal ellipsoids are drawn at the $50 \%$ probability level.

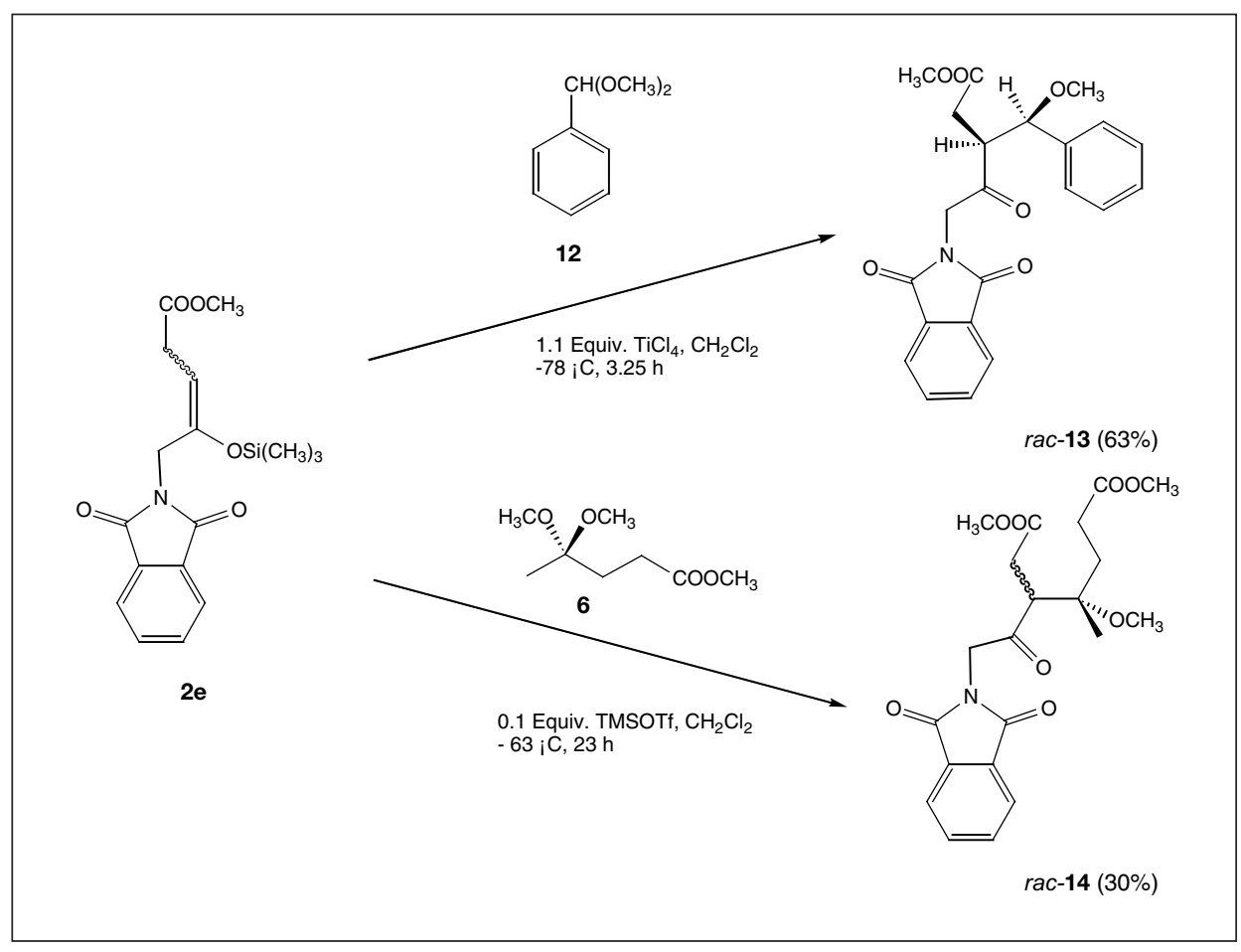

Scheme 8.

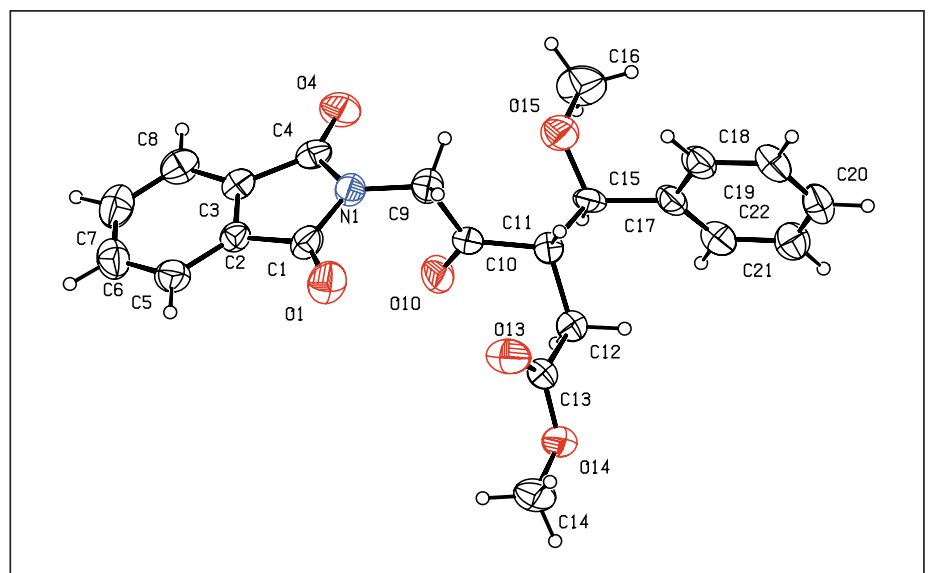

Fig. 3. Perspective view of rac-13 showing the crystallographic numbering scheme. The thermal ellipsoids are drawn at the $30 \%$ probability level. analytic sample was obtained by crystallization from acetone $/ \mathrm{H}_{2} \mathrm{O}$. The pyrazol 17 is structurally very similar to the PBG whereas the reactivity of the pyrazol 17 differs from the reactivity of PBG. The pyrazol is an electron-poor heterocycle. To deprotect the precursor $\mathbf{1 6}$ to obtain the pyrazol 17, heating over $24 \mathrm{~h}$ in $1 \mathrm{~N} \mathrm{HCl}$ can be applied without visible destruction of the final product. PBG and similar pyrrolic derivatives would not resist such drastic conditions. Heating PBG in the presence of an acid inevitably leads to the formation of porphyrins, pyrrol-oligomers, and pyrrolic polymers like the pyrrol black. Pyrazols are often present in the two possible tautomeric forms [26][33]. The X-ray structure of the protected pyrazol showed that in the crystal only one of the tautomeric forms is present. To obtain information on the presence and distribution of the two tautomeric forms in solution, a ${ }^{15} \mathrm{~N},{ }^{1} \mathrm{H}$ HMQC-experiment was performed. The signal resonating at $-170.7 \mathrm{ppm}$, which can be attributed to the $\mathrm{NH}$ of the pyrazols, correlates with the $\mathrm{H}_{2} \mathrm{C}\left(3^{1}\right)$-group of the propionic acid side chain. This observation is a clear indication that also in solution the same tautomeric form is preferred as observed in the crystal structure.

In summary we have developed a method for the synthesis of protected silyl enol ethers of the 5-aminolevulinlevulinate 2e with good regioselectivity. This silyl enol ether reacts with activated carbonyl compounds under carefully controlled Mukaiyama aldol reaction conditions. Starting with the monoester of succinic acid monochloride the diketone $\mathbf{1 5}$ could be obtained. From 15 the pyrazol 17, an aza-analogon of PBG, could be synthesized in two simple steps with high yields. The structural investigations of the protected pyrazol 16 showed that this compound is preferentially present in one tautomeric form. The pyrazoles $\mathbf{1 6}$ and $\mathbf{1 7}$ are considerably more acid-stable than the PBG itself and they are therefore potentially interesting inhibitors for the investigation of the tetrapyrrol biosynthesis.

\section{Supplementary Data}

Crystallographic data (excluding structure factors) for the four structures described here are deposited with the Cambridge Crystallographic Data Centre as supplementary publication nos. CCDC 211426 (1e), CCDC 211427 (10b), CCDC 211428 (rac-13), CCDC 211429 (16). Copies of the data can be obtained free of charge on application to the Cambridge Crystallographic Data Centre, 12 Union 


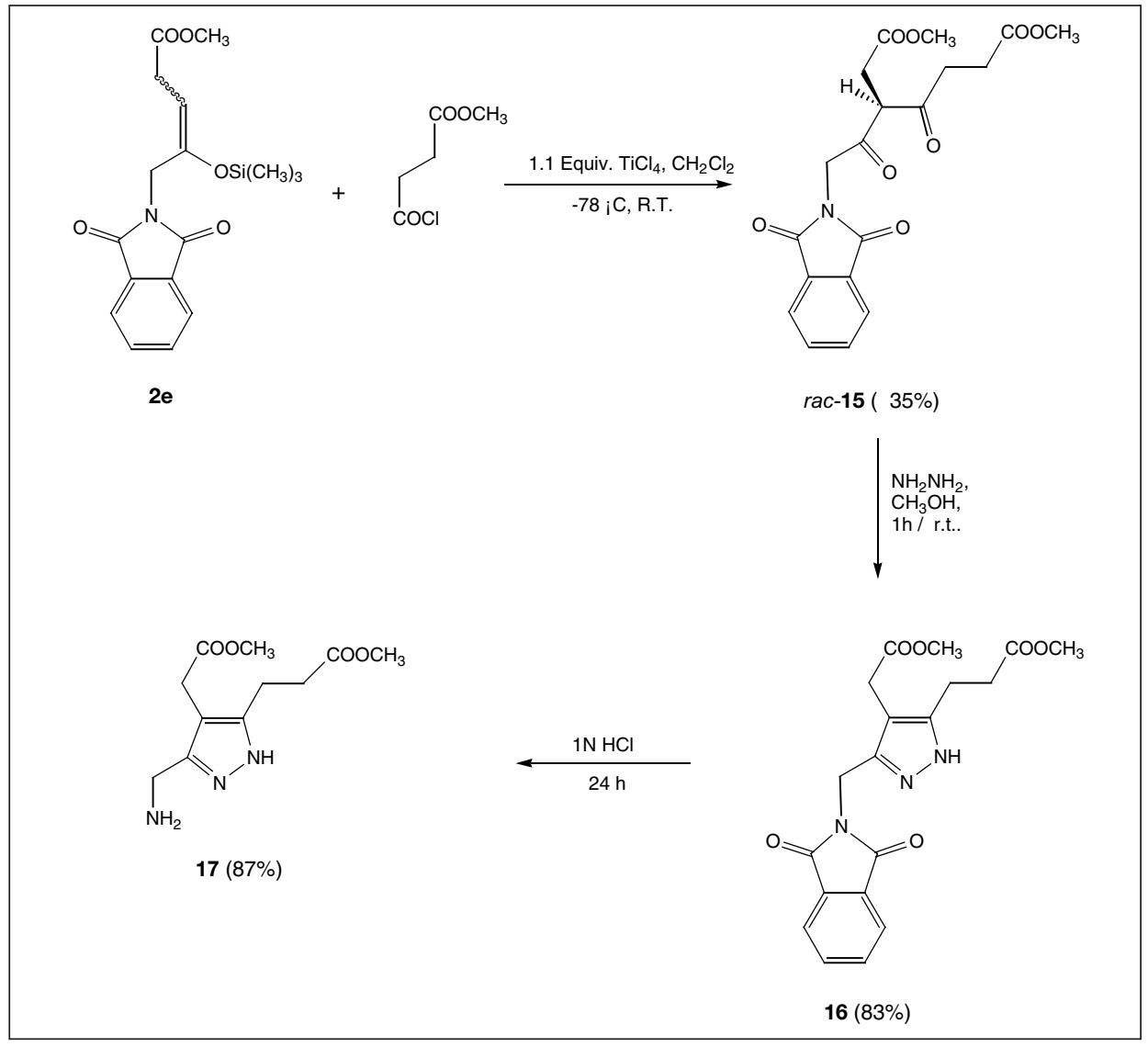

Scheme 9.

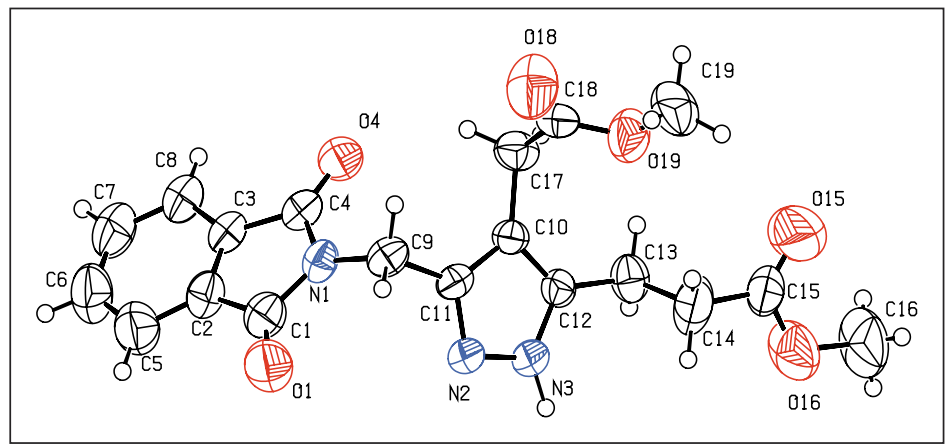

Fig. 4. Perspective view of $\mathbf{1 6}$ showing the crystallographic numbering scheme. The thermal ellipsoids are drawn at the $50 \%$ probability level.

Road, Cambridge CB2 1EZ, UK [Fax: (internat.) +44-1223/336-033;

E-Mail: deposit@ccds.cam.ac.uk].

\section{Acknowledgement}

The NMR spectra were measured by Heinz Bursian and Dr. Saturnin Claude, the MS by Dr. Yves Carraux and Dr. Mafalda Rama. Financial support of this research by the Swiss NSF and the University of Neuchâtel is gratefully acknowledged.
1972, 94, 8269-8271.

[8] C.E. Brown, J.J. Katz, D. Shemin, Proc. Natl. Acad. Sci. USA 1972, 69, 25852588 .

[9] A.R. Battersby, M. Ihara, E. McDonald, F. Satoh, D.C. Williams, J. Chem. Soc. Chem, Comm. 1975, 436-437.

[10] A.I. Scott, Accounts Chem. Res. 1990, 23, 308-317.

[11] A.R. Battersby, Natural Product Reports 2000, 17, 507-526.

[12] A.I. Scott, J. Org. Chem. 2003, 68, 2529-2539.

[13] R. Neier, in 'Advances in Nitrogen Heterocycles', Ed.: C.J. Moody, JAI, Greenwich, 1996, Vol. 2, pp. 35-146.

[14] P. Bobal, R. Neier, in 'Trends in Organic Chemistry', Vol. 6, SB Press, Trivandrum, India, 1997, 125-144.

[15] D. Mauzerall, J. Am. Chem. Soc. 1960, 82, 2605-2609.

[16] D. Mauzerall, J. Am. Chem. Soc. 1960, 82, 2601-2605.

[17] A.I. Scott, C.A. Townsend, K. Okada, M. Kajiwara, Trans. N. Y. Acad. Sci. 1973, 35, 72-79.

[18] B. Franck, H. Stratmann, Heterocycles 1981, 15, 919-923.

[19] A. Eschenmoser, Angew. Chem. 1988, 100, 5-40.

[20] G. Ksander, G. Bold, R. Lattmann, C. Lehmann, T. Früh, Y.-B. Xiang, K. Inomata, H.-P. Buser, J. Schreiber, E. Zass, A. Eschenmoser, Helv. Chim. Acta. 1987, 70, 1115-1172.

[21] D.L. Nandi, D. Shemin, J. Biol. Chem. 1968, 243, 1236-1242.

[22] A.R. Chaperon, T.M. Engeloch, R. Neier, Angew. Chem., Int. Ed. 1998, 37, 358-360.

[23] H. Bertschy, A. Meunier, R. Neier, Angew. Chem. 1990, 102, 828-830.

[24] A. Meunier, R. Neier, Synthesis 1988, 381-383.

[25] T. Mukaiyama, Org React, 1982, 28, 203331.

[26] J. Elguero, in 'Comprehensive Heterocyclic Chemistry II', Eds.: A.R. Katritzky, C.W. Rees, E.F.V. Scriven, Elsevier, Oxford, 1996, Vol. 3, pp. 1-75.

[27] R.D. Miller, D.R. McKean, Synthesis 1979, 730-732.

[28] H.O. House, L.J. Czuba, M. Gall, H.D. Olmstead, J. Org. Chem. 1969, 34, 23242336.

[29] S. Murata, R. Suzuki, R. Noyori, J. Am. Chem. Soc. 1980, 102, 3248-3249.

[30] C. Mukai, S. Hashizume, K. Nagami, M. Hanaoka, Chem. Pharm. Bull. 1990, 38, 1509-1512.

[1] B. Kräutler, Chimia 1987, 41, 277-292.

[2] A.R. Battersby, C.J.R. Fookes, G.W.J. Matcham, E. McDonald, Nature (London) 1980, 285, 17-21.

[3] P.M. Jordan, in 'Biosynthesis of Tetrapyrroles', Ed. P.M. Jordan, Elsevier, Amsterdam, 1991, p. 1-66.

[4] A.R. Battersby, F.J. Leeper, Chem. Rev. 1990, 90, 1261-1274.

[5] F.J. Leeper, Natural Product Reports 1989, 6, 171-203.

[6] B. Franck, D. Gantz, F.P. Montforts, F. Schmidtchen, Angew. Chem., Int. Ed. Engl. 1972, 11, 421-422.

Received: July 14, 2003 [7] A.I. Scott, C.A. Townsend, K. Okada, M. Kajiwara, R.J. Cushley, J. Am. Chem. Soc.
[31] A.P. Davis, M. Jaspars, Angew. Chem. 1992, 104, 475-477

[32] H. Sakurai, K. Sasaki, A. Hosomi, B. Chem. Soc. Jpn. 1983, 56, 3195-3196.

[33] J. Elguero, C. Marzin, A.R. Katritzky, P. Linda, 'Advances in Heterocyclic Chemistry, Supplement 1: The Tautomerism of Heterocycles', Academic, New York, 1976. 